Meta

Journal des traducteurs

Translators' Journal

\title{
Inuit DLT, Language Management and World Technology
}

\section{Dirmid Ronán F. Collis}

Volume 38, numéro 1, mars 1993

La traduction et l'interprétation dans le nord du Canada

Translation and Interpretation in Northen Canada

URI : https://id.erudit.org/iderudit/002351ar

DOI : https://doi.org/10.7202/002351ar

Aller au sommaire du numéro

Éditeur(s)

Les Presses de l'Université de Montréal

ISSN

0026-0452 (imprimé)

1492-1421 (numérique)

Découvrir la revue

Citer cet article

Collis, D. R. F. (1993). Inuit DLT, Language Management and World Technology. Meta, 38(1), 73-81. https://doi.org/10.7202/002351ar

\section{Résumé de l'article}

L'article traite de l'utilisation d'un langage de traduction standardisé afin d'unifier le monde des langues inuktitut-inupiaq. Ceci contribuerait à donner aux diplômes obtenus dans chaque sous-dialecte de la langue inuit une valeur égale à ceux obtenus dans des langues plus largement répandues. On discute également des techniques de DLT, de ses avantages économiques et procéduraux ; d'écologie du language et de ce que cela représente pour les locuteurs et les non-locuteurs de l'inuktitut. Le rôle que la traduction technique joue dans le maintien des droits linguistiques est également évoqué, ainsi que l'emploi qui serait fait des traducteurs-terminologues en inuktitut si une politique d' "accès à l'information" était adoptée, rendant ainsi les connaissances techniques et scientifiques accessibles aux ¡nuit. On suggère que la traduction non culturelle devienne un droit pour les peuples et que la Conférence circumpolaire inuit (CCI) en fasse une proposition à Genève. Enfin, on montre comment et pourquoi l'inuktitut pourrait devenir un véhicule efficace de la connaissance.
Ce document est protégé par la loi sur le droit d'auteur. L’utilisation des services d’Érudit (y compris la reproduction) est assujettie à sa politique d'utilisation que vous pouvez consulter en ligne.

https://apropos.erudit.org/fr/usagers/politique-dutilisation/ 


\title{
INUIT DLT, LANGUAGE MANAGEMENT AND WORLD TECHNOLOGY
}

\author{
DiRMid RonÁN F. COLliS
}

Université Laval, Quebec, Canada

\begin{abstract}
Résumé
L'article traite de l'utilisation d' un langage de traduction standardisé afin d' unifier le monde des langues inuktitut-inupiaq. Ceci contribuerait à donner aux diplômes obtenus dans chaque sous-dialecte de la langue inuit une valeur égale à ceux obtenus dans des langues plus largement répandues. On discute également des techniques de DLT, de ses avantages économiques et procéduraux; d'écologie du language et de ce que cela représente pour les locuteurs et les non-locuteurs de l'inuktitut. Le rôle que la traduction technique joue dans le maintien des droits linguistiques est également évoqué, ainsi que l'emploi qui serait fait des traducteurs-terminologues en inuktitut si une politique d" "accès à l'information» était adoptée, rendant ainsi les connaissances techniques et scientifiques accessibles aux Inuit. On suggère que la traduction non culturelle devienne un droit pour les peuples et que la Conférence circumpolaire inuit $(C C I)$ en fasse une proposition à Genève. Enfin, on montre comment et pourquoi l' inuktitut pourrait devenir un véhicule efficace de la connaissance.
\end{abstract}

\begin{abstract}
This article deals with the use of distributed language translation (DLT) to unite the Inuktitut-Inupiaq-speaking world, giving its school diplomas equal value in each Inuit regional language to those in more widely-spoken languages. It discusse: the DLT technique, its economic and procedural advantages; language ecology and what it means to speakers and non-speakers of Inuktitut: the role that technical translation can play in maintaining language rights; what would be the role of the Inuit translator-terminologist if a "right to know" policy were adopted making available technical and scientific knowledge to the Inuit through their language. It suggests that non-cultural translation may be a People's right which ICI could advance at Geneva. Finally it shows how Inuktitut can become as efficient a language vehicle for knowledge as either Hungarian or Japanese, and why.
\end{abstract}

\section{THE BACKGROUND TO TRANSLATION AS A MEANS OF SPEECH-COMMUNITY SURVIVAL}

\section{Language as Behaviour}

Linguists who specialize in the study of language as a code often put aside the consideration of language as behaviour. Yet one can compare the use of language by an individual to the operating system of a computer. Every operation that a computer does: sorting, comparing, copying, substituting, ordering etc. is governed by the system on which the computer runs. If you introduce more than one operating system into a computer confusion occurs. Similarly, the human being's capacity to remember, learn and function in society is influenced by the system of the language he uses. Just as it is possible to alternate the operating systems of some computers so it is likewise possible for a bilingual individual to alternate the languages he uses to remember, learn and function in society. Yet, the more flexible the computer, the slower its operation and the more linguistically flexible the person the slower he also he can respond to his needs. When two or more languages are commonly used in ordinary daily life the amount of energy that the individual has to use just to communicate is doubled or trebled. So, except in the case where a person has exceptional skill in keeping two languages apart, (statistically 
this was found to be one person in 1,400 in a Quebec evaluation of the translation methods of second-language teaching in 1959) the speech community that uses more than one language puts itself at a psychological disadvantage save when the use of the second or third language is reserved for exceptional circumstances. It can also be argued that the advantage of having the mastery of more than one language is that when a person so endowed is subject to no stress his considered opinion on almost any matter involving other speech communities will tend to be fairer and more impartial than that of a monolingual. Inversely, when he is subject to stress he will have greater difficulty in defending himself. In all cases where the individual is not a person of exceptional linguistic ability he is at his best when he can use more than one language but is only required to do so in exceptional circumstances.

\section{The Problem of Language Shift}

When a person of no special linguistic ability is obliged to express himself in two languages in ordinary circumstances, his unconscious tendency will be to use as little energy as possible. So, if the more important things in his life, such as earning a living, require him to use one of his languages more than the other his tendency will be to favour the language which he uses for the more important functions. Even if he expresses loyalty to his first language when he is asked to think about it, his behaviour (in this instance the quantity of words rather than what they mean) will determine definitely which language is more important to him. For this reason, it is possible to poll people for their language preference and then discover that their deeply-held opinions do not correspond to the facts of their behaviour. So the competence of bilingual people tends gradually to shift from being dominant in one language to dominant in the other (Mackey 1989). Again, the person of exceptional linguistic ability is capable of choosing which language to use much more consciously and his speech will show much greater consistency between his language loyalty and his behaviour. Yet he is the 1/1,400 exception, so to recommend generalised bilingualism for the ordinary circumstance of daily life is to adopt a strictly elitist policy, something that is virtually untenable in a modern democracy.

\section{The Problem of Language Survival}

The main problem of language survival is perceived need. If, in the view of its speakers, a language is seen as useless, it dies. I write as a person whose national language Irish (Gaelic) was suppressed, the books were burned and the scholars were exiled. Attempts to revive the language after political independence was achieved in Ireland have not been a success because the revivers propagated romantic patriotism rather than answering social needs. It may be said that early attempts in the 17th, 18 th, 19 th centuries to suppress Irish by punishment failed, just as the English-only boarding school in Aklavik failed in the 1950s to suppress Inuktitut. It was when famine was permitted in Ireland and food was offered by the colonial administration if the people would change their culture, followed by a more lenient social policy, that the people began to collaborate, to become bilingual, speaking Irish at home and English at work (Defrein 1969). Similarly, a few junior grades were offered in Inuktitut in the Hamlet schools of the NWT, yet despite this bilingualism, English spread throughout the NWT (Dorais 1989). In the Irish case, soon all that was needed to earn a living was supplied by the English language. Only people who lived the traditional life of fishermen, farmers and shepherds found their needs completely satisfied by their own language. But when the type of food allowed to the people (potatoes) increased the population rapidly, only some of them could remain on the land; the rest had to learn new skills. They could have learned them through their own language if the colonial administration of Ireland had been as tolerant of Irish language educational publications as the Hungarian administration of Magyar 
publications in the Austro-Hungarian Empire. However the colonial administration of Ireland, just as the Russian and German colonial aministrations of Poland at the same time, was interested in obliterating the national identity. What happened during the time of language change in Ireland was an unofficial diglossia similar in many respects to the cliglossia of the Canadian Inuit.

Diglossia is a term currently used to speak about the social or more properly, societal, equivalent of the bilingualism of the individual. When, in a society, two languages are used they are divided, usually according to need. The division falls into functional fields of usage: the mother language is perhaps used for worship, song, story telling, love-making, the second language for study, work, travel, law and business (the distribution of the functional fields of usage varies in the case of each diglossic society and two thirds of the world's 5 billion people are either diglossic or polyglossic). If the functional fields of usage favour the second language over the first, then gradually, the people begin to feel that the second language is more important than the first, particularly those who get good jobs and are able to be generous to their friends and relatives. Then occurs a language-devaluation syndrome which causes people to relativize their language, to consider it just one way of speaking among many. When the whole speech community has this syndrome a whole room full of people will tend automatically to switch languages to accommodate a single visiting stranger whose language is known, rather than expecting him to try to speak the language of the people. They may console themselves that they are more linguistically capable than the stranger, but they are also at serious psychological disadvantage. This is because their own evaluation of their own language relative to the stranger's language is influenced by the functional fields of usage to which it is put. This can even have the effect of giving more importance to what the monolingual stranger says if he talks about anything in the functional fields of usage for which his language is currently used. The individual's bilingualism is influenced by his people's diglossia. If he feels that his future is more influenced by his second language he will tend to associate his mother language with the past and look down on his parents and grandparents; at the same time he will feel inferior to, or dependent on, those who speak his second language as a first language. This can have the debilitating effect of depriving him of all initiative even as it robs him of self-esteem. Depending also on his parents' use and mastery of the second language, his own ability in both languages will vary. It can happen that in a diglossic society a person socially advantaged or wealthy, may yet have difficulty in keeping the two languages apart and so speak a creole or blended language, borrowing words from the second language to talk of new things when using their mother language. It is possible to have a perfectly satisfactory diglossic society provided that all the needs of the people and all the functional fields of usage are covered by the mother language. Then, and only then, is bilingualism additive, that is, adding culture and psychological strength. In cases where diglossia forces the use of the second language in more important fields of usage, the bilingualism of the individual is subtractive, that is, taking away the culture of the mother language without increasing the culture of the second language. Diglossia can produce either cultivation, when additive, or acculturation when subtractive (Mackey 1989).

Relevant to language survival is the question of language restoration. This is justified when a people has been partly acculturated and yet wants to maintain its identity as a people. However, the psychology of diglossia is still inescapable. Children taught through a language which is not their first language are disadvantaged. What can be done is to teach the children how to express all that they have learned through their first language (in this instance, the non-ethnic language) also in the ethnic language. But it should be noted that this will require considerable work on the ethnic language in terms of language 
management and translation; also, the use of the ethnic language must produce concrete benefits to the learner and not mere sentimental satisfaction; finally, the subconscious and conscious attitudes of the parents to the ethnic language must be very positive.

\section{The Legal Status of the Inuit Language}

Outside the province of Quebec where the Inuit language's legal status is additionally defined in concrete terms relevant to schooling in the James Bay Agreement, the legal status of Inuktitut reposes on two legal documents: The Rights of Man as defined in the Charter of the United Nations, to which Canada is a signator, and the Canada Act of 1982, Part II, articles (1), (2) and (3). The former recognizes the rights not only of persons but also of peoples and in so doing establishes a speech community, or community marked by the use of a different language as a distinct society, with all the rights of such a society. (The fact that Canada has signed the UNO charter means that, theoretically, it recognizes as many distinct societies as their are First Peoples who have maintained their languages, and also the distinct societies of the two Founding Nations in Canada). The latter, the Canada Act, recognizes the right of the Inuit to their language, but does not define in concrete terms how this right is applied. The Inuit in redress of their rights have access to the International Court at The Hague (by virtue of the Canadian signature to the UN Charter) and to the Supreme Court of Canada (by virtue of article 3 of the Canada Act) and to the Non-National Peoples' Assembly of the UNO in Geneva (by virtue of the Canadian signature to the UN Charter) (Collis 1990).

\section{The Political Economy of Inuit Language Use}

The use of a language in an established state is set within the constitutional framework. Its use is protected either in terms of the legal obligation of the state to constituent communities as well as to persons, as in Canada, in the European Community or in terms of the obligation of the state to protect the rights of individuals as in the United States of America. Within the constitutional framework the wellbeing of the language in its speech community can be calculated in terms of macro-economics. The econometrics of macroeconomics relative to language use takes as its constant the maintenance of the language. So the variables to be calculated are the most efficient factors available to this end. The Inuit have inherited an educational system from a time when econometrics even in macro-economics was calculated in terms of scale. In other words, a school curriculum for Inuit was considered sustainable if books and teaching cost no more than they would if the southern school was transported up north. For this reason, when bilingual (Inuktitut-English) schooling was extended to the Inuit schools no enabling legislation was made to cover the cost of the necessary language management. Without language management there is no standard or equivalent terminology for teaching scientific or technical subjects in the Inuktitut language and no manuals can be produced for teaching them. This means that despite a more gradual transition from Inuktitut to English in the school curriculum, no real equivalence between the functional fields of language use is planned. So the marginalization of Inuktitut continues. Prior to the UNO recommendation in 1977, when it was calculated that conditions of world food supply were not infinitely expandable and the use of scale calculus in macro-economics would guarantee world economic disaster, it was not perceived that there was a conflict between the priorities of human rights and of the calculus of scale when the latter is applied to macro-economics. Today this is recognized, but as yet the consequences (of fundamental institutional change in education and the implication of fundamental research on the Inuktitut language) have not, as yet, been considered in Canada so as to enable the school to be used in the interests of Inuit society. 


\section{The Role of Language Ecology}

Survival concerns not merely feeding bodies, but ensuring that the societies in which they are found may also survive. Human survival depends upon internalized struggle. The struggle produces adaptations to changing planetary conditions. Faced, struggle produces peaceful competition between the different conceptualities of the different societies. Each language is a repository of a particular set of conceptualities. When a device is invented by one language community it may be adopted by another, always provided that it does not come into conflict with the societally-held values of the second society. When the internalized struggle involved in expanding consciousness is rejected by a speech community, it may produce aggressive, prejudiced behaviour or even war. The expanding of consciousness in a society implies that individuals are trained to adopt strategies to channel defence impulses into socially useful reflexes. The Danish strategy delays defense impulses by subjecting them to rationality. The Inuit strategy channels defence reflexes to the functional field of hunting. This kind of mental hygiene works as a social force quite naturally in Inuit society (Briggs 1968, 1979). It puts the Canadian Inuit at a disadvantage when faced with the aggressiveness of Southern Canadians who are not, like the Danes or the Inuit, reared to practice this form of mental hygiene. The struggle of adaptation to living in different parts of the planet forces people to develop different patterns of thought which are expressed in the different languages. Each of these languages, because of its specialization, also adds to the survival skills of all living human beings. But each language also, beside the things which it expresses overtly by signs, also signals by implication a great many things that are taken for granted by the speech community and are seldom, if ever, mentioned. These inferences tell what is expected of an individual so that he may function successfully in his community. For instance, in the Inuktitut-speaking world it is very bad form to boast or even to state an opinion too directly. In the American-speaking world, inversely, some boasting is expected as a sign of a healthy ego. Similarly, fellowship, in the Inuktitut-speaking world, is expressed among the people whom a polite person will never address by name: his extended family relatives. In the American-speaking world it is even permitted to address one's parents and grandparents by their first name, because there, the paragon of friendliness is not the hierarchical family structure but the peer group.

\section{Language and Communication}

It is often asked if the world would not be a better place if there were less than the roughly 6000 languages which still exist. The question is most often raised by those who live in a vast speech community, have travelled very little and understood even less when they did. Thinking of the kind would have it that, since the industrial revolution started in England, and since today $60 \%$ of all scientific journals in the world are printed in English it would be easier if everyone spoke only English, or used only English for scientific and technical data. That same kind of thinking has reduced the number of species of animals, birds, fish and plants. But the world changes and the smaller the number of species the less likelihood of survival of life itself on the planet. Likewise each language was built in a particular environment and has its own kind of influence on the way its speakers think. While science and technology have spread and brought longer life the survival of the human species depends upon the will to struggle. Likewise, in order that the languages be maintained they must be used in every functional field of use. Finally, in order that the languages can be used for everything, all technical information that is not already available in them must be translated into them. 


\section{DLT AS THE EFFICIENT FACTOR IN LANGUAGE RIGHTS}

How can one translate everything technical into every language? Certainly not by working with a pencil and a dictionary. (The situation in the European Community at first was such that everything official had to be translated by hand into the nine majority languages at a cost of $\$ 15$ per word of every administrative text! - leaving the thirty-two lesser-used West-European languages out in the cold). Then a solution was found in Utrecht, Netherlands in a systems-developing company call BSO (Büro Systems Ontwikling 1 ). The system invented by BSO is computer-assisted translation of a special kind known as distributed language translation (DLT).

First, computer-assisted translation is a gradually increasing set of steps toward automated translation. Because natural languages are economical they can use words in several ways and in each way they are used they have a different meaning. In each language the number of ways of using words and what the words are used to mean is special to that language. So the first problem in automating translation is that it is not always possible to tell from the text which meaning is the right one in the context. A person reading a text brings his knowledge to his reading, knowledge of the world outside the language. Until a computer can be programmed with "real world" knowledge, inferences must be resolved by human translators working together with the machines. The machine is most helped in its translation task if the input message in the source language is first rendered completely clear. So, computer-assisted translation has the computer read the text of origin in the source language and then send a message on the computer screen to the translator in his or her mother language asking him or her to decide which meaning is right for each word with several meanings, usually by pressing keys $\mathrm{A}, \mathrm{B}, \mathrm{C}$, or D on the keyboard. As soon as this step is completed the message is, for the first time, sufficiently clear for the computer to substitute the right words in the right order in the target language. This technique has been widely adopted in the European Community and Canada.

Distributed language translation (DLT) goes one step further in automation by using an Interlanguage (IL). An Interlanguage for DLT is an artificial language for the use of the computer. The difference between a computer IL and a natural language is that in the IL words may have only one meaning and one class (or part of speech). Everything in an IL is absolutely regular and without any exception whatever. The use of an IL means an enormous saving in the number of computer systems needed to translate between several natural languages ${ }^{2}$. Since natural languages are variables (with words with several meanings and belonging to several parts of speech), direct computer translation from one natural language to another requires programs equal in number to the square of the number of languages to be translated, because direct translation between natural languages can only be monovalent or one-way. When an IL is used the number of programs required is equal to the sum of the languages to be translated plus one, the IL; because the IL is a constant. So if one wanted to translate between eight natural languages without an IL one would need 64 programs, but with an IL only 9. BSO uses Esperanto as its IL for the following reasons: Esperanto is completely regular with regard to parts of speech; by convention, for the purpose of the IL, Esperanto words are used with only one meaning; it is to be used between European languages and is based upon Latin with additional modern words borrowed from the modern European languages but adapted to the phonological and morphological conventions of Esperanto and so it is very easy for Europeans to use; there are 500,000 people who use Esperanto as a second language; it has already a fixed style which all respect; it is much easier to use a language for an IL than a set of codes which are hard to remember when programming. Incidentally, while I do not advocate Esperanto for the first stage of Inuktitut translation, Victor Sadler, an expert in Esperanto and its application 
to DLT has demonstrated that it is so flexible as to be able to be written in long agglutinated words like Inuktitut or Hungarian. DLT can nowadays be managed efficiently on a powerful microcomputer or a work station.

The problem of translating into or from Inuktitut in Canada alone (even leaving out Greenland, Alaska and the USSR where there are also Inuit with the same needs) is that there are 8 Canadian regional varieties of Inuktitut, even if they blend a bit at the edges of the areas in which they are spoken. For instance the expression piaraqtaaqtuq (pi-araqtaaq-tuq) means "she has a child (adopted or natural)" in Nunavik, Quebec, but in the Boothia Peninsula (Gjoa Haven, Spence Bay, Pelly Bay) it means "an animal has brought forth young;" the word aliasuktuq (alia-suk-tuq) in the former means "happy, joyful" and in the latter "scared, aggressed" (the word was originally used about the combination of awe and joy that people felt when the raven dance was performed to the drum in celebration of the creation of light in the old religion).

The most useful first application of DLT to Inuktitut would be to unite all the varieties of Inuktitut. It is possible to make an Inuktitut IL based on a calculus of interlingual distance (Mackey 1979) (the mean phonology, the mean morphology, the mean syntactic class, the mean semantic content), using a phonological adaptation of the morphology of all the dialects to achieve the required one-word/one-meaning for the IL. Such an IL would be as easy for Inuit language specialists to use as Esperanto is to Europeans. Once this IL was built, then an interface would have to be made for each of the regional languages. Then all the Canadian regional Inuit languages would be united by computerassisted translation. This would enable equal school curricula everywhere and diplomas with a recognized standard and value. Then it would be possible to interface the Inuktitut IL to the Esperanto IL and make it possible for all the technical knowledge from the 1 million European scientists (and 300,000 North American scientists) to flow into Inuktitut as required, but not before the Inuktitut regional languages were joined by computers so that there could first be a united Inuit public opinion with the help of a terminal in every hamlet and township.

The process of DLT uses a strategy quite different from exclusively human translation. When one plans for humans one has to remember that they have enormous memories but think below the speed of sound; but when planning for computers, that they have tiny memories but operate at the speed of light. For the human translator the strategy is to promote all linguistic data to the highest level, so syntax is merged with semantics, morphology moved up into syntax, and phonology into morphology. With a computer the reverse strategy must be followed so semantics is brought down to syntax, syntax to morphology and morphology to... letters. This being the case, the job of the computer is the evaluation and substitution of sets of discrete units.

\section{The Categories of Inuktitut}

A word or two about how Inuktitut is organized as a language. Inuktitut shares a large number of morphosyntactic similarities with Finno-Ugric, Korean, Mongolian, Uzbek, Turkish, Niv and Japanese such as: (1) instead of nominal declensions, lexically independent case suffixes are attached to nouns; (2) instead of verbal inflections, independent mood and person suffixes are attached to verbs or agglutination of auxiliary elements is used to form a predicate phrase; (3) instead of prepositions, there are postpositions; (4) there is often a subordinate conjunction at the start of the subordinate clause; (5) the verb complex is sentence-final; (6) there is no grammatical gender. Distinct from the Altaic languages, there is an interrogative verbal mood. Distinct from Hungarian, the Inuktitut stem may contain only one base morpheme. Typologically it is generally considered to be agglutinative, polysynthetic and hyper-centrifugal (topic followed by comment). Gram- 
matical roles such as subject, object, agent, patient, instrument or locative are often expressed solely by suffixes in Inuktitut sentences. As in Japanese, adjectives and verbs use identical suffixes. The hinging argument of the verb is not restricted to the predicative criterion, but can suppress this in favour of agentive, instrumental, partitive or existential criteria, usually in the third person or non-person (morphologically, in the third person, the verbal mood sign is followed only by marks of singular, dual and plural). Word forms are morpheme-sequences consisting of a stem and several grammatical morphemes with additional syntactic information such as person, possession and so on. Roughly, a word is an adverb, a conjunction or a noun/verb/adjective phrase. The discrete units in Inuktitut are not limited to words but also include morphemes and morpheme clusters. So the input message when translating with the help of a computer out of Inuktitut (either to a different regional language or to a language of an entirely different family) is the output of a word parser. A word parser breaks down words into their functional elements. Beyond stems in Inuktitut which form the classes of Noun, Verb, Pronoun, Adjective, Adverb, Numeral, Situative and Subordinate and Coordinate Conjunctions there are also affixes which form four classes of auxiliaries: Auxiliary Adjectives, Auxiliary Adverbs, Auxiliary Verbs and Auxiliary Participles, suffixes which include Postpositions, Cases, Moods, Person Subject, Person Object, Person Relative and Person Possessor and finally enclitics which are functionally Auxiliary Conjunctions. For the computer's sake these have to be isolated by a parser because an Inuktitut sentence may be just one long word such as (in Natsilingmiut regional language):

pijuminaqtiraqtuq, "he considers him to be one who does things properly, (or wants to do things well)."

In order to record a structure which is as explicit of dependency as those of more isolating languages for the purpose of distributed language translation (DLT), this sentence has to be passed through the morphological analyzer and a dependency tree built from its output.

It should be mentioned that the DLT system is user-friendly. It considers the needs of translators, (to make decisions rather than leaving them the drudgery of substitution), of linguists (who can check data for programming more easily when it is displayed graphically as stema or trees of dependence) of computer programmers who require absolutely "clean" data. Further, it enables constant development toward greater and greater automation on a pay-as-you-say basis. In other words it provides help to the translator right from the start while offering him or her the chance of developing improved devices (translation for different subjects, for different age groups, correlation with pictures for teaching, etc.). When Canada plunged into completely automated translation directly between two natural languages even for even a single very dry subject such as meteorology, it cost millions, whereas the DLT master system outlines a path for gradual and continued improvement which is adaptable to all of Canada's 42 languages (the "official" and the First Peoples' languages that it has signed the UNO charter with a pledge to respect).

\section{Language Maintenance and Technical Expansion}

Until World War II European powers who first extended the science and technology they had imported from the older civilizations of China and Egypt tended to equate them ( $\mathrm{S} \& \mathrm{~T}$ ) with their own cultures. By exporting their technical devices and systems through trade or colonialism the Europeans gave the world a planetary technology and scientific knowledge which found thousands of different applications in different parts of the world. Then these applications led to new inventions to serve different cultures without necessarily destroying the essential life-style of the countries that adopted the tech- 
nology. What did destroy many cultures was when the micro-economic calculus of scale was applied to the macro-economics of statecraft. In scale economics it was considered cheaper to build schools and teach through a foreign language. In post-colonial factor economics, it is considered more profitable to follow the shortest route to learning. The shortest route to learning is the mother language. Expansion and technical reunification of the mother language so that it can handle all the science and technology, so that they may compete in the world as a people, can only be done in terms of perceived need. That need is perceived only when the translator has to struggle to develop terminology to translate systems and ideas, science and technology, automating as he goes. Language management is technically-assisted language planning done with the consent of the people when they perceive the need for it.

\section{Notes}

1. BSO is not a software company, selling packaged data processing. It sells systems from which dataprocessing may be developed.

2. It is assumed that there is a societal need to access world science and technology. This implies planning for the possibility of multilingual translation. Where a private company in a majority society where the language is in no danger might question the usefulness of a multilingual translation method, a society, a people, whose language is in danger, is in a very different circumstance. Massive translation directly from one language to another brings with it the danger (eliminated by use of an IL) that the science and technology be presented in the terms and concepts of the source language. Translation of technology is something vital to the preservation of the culture of a people. Without it they cannot compete in a globalized world. Yet direct translation into a disadvantaged language can have the effect of backgrounding the native conceptuality if the cultural content of the expression of that science and technology in the source language is not eliminated in translation to the target language.

\section{BIBLIOGRAPHY}

BRIGGS, Jean (1979): Aspects of Inuit Value Socialization, National Museums of Canada, 63 p.

BRIGGS, Jean (1968): Utkuhikhalingmiut, Eskimo Emotional Expression, Department of Indian Affairs and Northern Development, $\mathrm{XV}+74 \mathrm{p}$.

COLLIS, D. Ronán F. (1990c): "Dependency Syntax of Natsilingmiut", The Natsilingmiut Language: A Grammatical and Lexical Outline as an Aid to Inuktitut DLT, (forthcoming).

COLLIS, D. Ronán F. (1990b): "Le statut des langues autochtones au Québec", Les langues autochtones de Québec, Québec, Conseil de la langue française, (forthcoming).

COLLIS, D. Ronán F. (1990a): "The Inuit People of Canada", The People of the Arctic, History and Current Conditions, Paris, Unesco, (forthcoming).

COLLIS, D. Ronán F. (Ed.) (1989): The Arctic Languages, an Awakening, Paris, Unesco, (forthcoming).

COLLIS, D. Ronán F. (1988b): "The Application of Translation Technology to Language Management, The Case of the Inuit in Canada", L'Actualité Terminologique - Terminology Update, Bulletin of the Translation Bureau, Secretariat of State of Canada.

DEFREIN, Sean (1969): The Great Silence, Mercier Press, Dublin \& Cork.

DORAIS, Louis-Jacques (1989): "Bilingualism and Diglossia in the Canadian Eastern Arctic", Arctic, 42-3.

MACKEY, William F. (1989): "La genèse d'une typologie de la diglossie", Revue québécoise de linguistique théorique et appliquée, 8-2.

MACKEY, William F. (1979): "Determining the Status and Function of Language in Multilingual Society", Status and Function of Languages and Language Varieties, Ulrich Ammon, Walter de Gruyter, Berlin, New York, p. 3-20, Université Laval, Centre international de recherches sur le bilinguisme (CIRB) Serie D 90.

MACKEY, William F. (1979): La distance interlinguistique, Université Laval, CIRB, Serie B-32.

MACKEY, William F. (1978): A Calculus of Language Difference, Université Laval, CIRB, 14-12-79.

MACKEY, William F. (1969): La rentabilité des mini-langues, Publication B-5, Université Laval, CIRB.

MAXWELL, Dan and Klaus SCHUBERT (Eds) (1989): Metataxis in Practice, Dependency Syntax for Multilingual Machine Translation, B.S.O. Foris Publications 6, Dordrecht, Holland \& Providence, Rhode Island.

MEL'ĆUK, Igor A. (1988): Dependency Syntax: Theory and Practice, SUNY Series in Linguistics, State University of New York, Albany, New York University Press.

SCHUBERT, Klaus (1987): Metataxis, Dependency Syntax for Multilingual Machine Translation, B.S.O. Foris Publications 2, Dordrecht, Holland \& Providence, Rhode Island.

SADLER, Victor (1989): Working With Analogical Semantics: Disambiguation Techniques in DLT, B.S.O. Foris Publications 5, Dordrecht, Holland \& Providence, Rhode Island. 